\title{
Young anesthesiologists, be a frontline respiratory researcher
}

\author{
Shiroh Isono $\cdot$ Michiaki Yamakage
}

Received: 27 October 2010/Published online: 14 December 2010

(C) Japanese Society of Anesthesiologists 2010

Our forerunners in respiratory research have extensively elucidated the pathogenesis of various respiratory diseases and developed diagnostic and treatment strategies for the diseases. Starting from simple structural and functional assessments of the respiratory system using airflow measurements and airway-imaging techniques, recent neurophysiological, immunological, and genomic approaches have further advanced our understandings of causes and processes of the diseases. Pharmacological inventions and improvements, for example oxygen, antibiotics, antiinflammatory drugs, and bronchodilators have significantly reduced mortality from respiratory diseases. Technical advances, for example the endotracheal tube, clinically usable blood gas analyzers, pulse oximeters, and sophisticated ventilators have enabled us to intensively care for patients with respiratory failure.

We anesthesiologists should be proud of our anesthesiology ancestors' contributions to many of these breakthrough findings and inventions for clinical management of patients with respiratory diseases. For example, how many young anesthesiologists know who invented and developed the blood gas electrodes? Professor John W. Severinghaus, an anesthesiologist, recollected the need to maintain

Opening remarks for $2010 \mathrm{~J}$ Anesth annual symposium on "Contributions of anesthesiologists to frontline research and treatment of respiratory diseases".

S. Isono $(\bowtie)$

Department of Anesthesiology, Graduate School of Medicine, Chiba University, 1-8-1 Inohana, Chuo-ku, Chiba 263-8670,

Japan

e-mail: shirohisono@yahoo.co.jp

M. Yamakage

Department of Anesthesiology, Sapporo Medical University

School of Medicine, Sapporo, Japan consciousness in World War II pilots who needed to fly higher, adequate ventilation in Polio patients, and normality of blood acid-base during hypothermia and cardiac bypass; this made him interested in respiratory research and motivated him to invent blood gas electrodes [1]. Although he is talented in physics, electronics, and physiology, he would not have accomplished his great contributions to medicine without his clinical experience as an anesthesiologist and his passion for translational medicine. It is not surprising that many Japanese anesthesiologists contributed to the discovery and development of pulse oximetry by Dr Takuo Ayoyagi [2]. John states, "I submit that research was largely responsible for translating anesthesia from a surgical service into its central role in academic medicine and its many roles in today's health care", and at his conclusion, "When technology is master, we shall reach disaster faster (by Piet Hein)". We have not yet achieved our objectives as medical scientists and clinicians. There is still so much for us to do. Young anesthesiologists, follow our great ancestors, and be frontline respiratory researchers with the advantages of being anesthesiologists.

\section{References}

1. Severinghaus JW. Gadgeteering for health care: the John W. Severinghaus lecture on translational science. Anesthesiology. 2009;110:721-8.

2. Aoyagi T. Pulse oximetry: its invention, theory, and future. J Anesth. 2003;17:259-66. 